\title{
Subsurface flow contribution in the hydrological cycle: lessons learned and challenges ahead-a review
}

\author{
Mehdi Ghasemizade - Mario Schirmer
}

Received: 12 July 2012/Accepted: 14 February 2013/Published online: 5 March 2013

(c) Springer-Verlag Berlin Heidelberg 2013

\begin{abstract}
Subsurface flow to maintain base flow and its contribution to high flow is of high significance. The high contribution of subsurface flow to stream flow has usually been determined based on the application of tracers. However, there are some studies that challenge tracer test applications. These studies have shown that tracer test applications lead to a high percentage of subsurface flow contribution because advection and dispersion effects are not individually considered in the mass balance equation. On the other hand, there is yet no broad consensus on the responsible mechanisms that justify high contributions of underground water to river flows. In this paper, we focus on the contribution of subsurface flow to high flows, although a brief description of their role in low flows is included. We discuss different suggested mechanisms, considering their applicability, strengths and inadequacies. In addition, the application of tracer experiments is elaborated. Finally, the challenges of modeling surface/subsurface flow interactions are addressed, followed by a short description of our future targets.
\end{abstract}

Keywords Event/pre-event water · Hill slope . Capillary fringe $\cdot$ Storm flow $\cdot$ Subsurface flow

M. Ghasemizade $\cdot$ M. Schirmer

Water Resources and Drinking Water Department, Eawag, Swiss Federal Institute of Aquatic Science and Technology, Ueberlandstrasse 133, 8600 Dübendorf, Switzerland

M. Ghasemizade $(\square) \cdot$ M. Schirmer

Centre for Hydrogeology and Geothermics (CHYN),

University of Neuchatel, Neuchatel, Switzerland

e-mail: mehdighasemizade@ymail.com;

mehdi.ghasemizade@eawag.ch

\section{Introduction}

Despite the fact that groundwater and surface water are often hydraulically interconnected, they are traditionally considered as two separate systems and are analyzed independently. Such a separation is partly due to the belief that groundwater movement has a much larger timescale than that of free surface water movement, and partly due to the difficulties in measuring and modeling their interactions. There exist extensive hydrodynamic models, with different levels of complexity that treat the surface and subsurface flows independently. Nevertheless, the importance of considering the surface water and groundwater as a single body has become an increasing necessity, in terms of both high flows/peak flows/floods and low flows/base flow (Winter et al. 1998; Liang et al. 2007; Weill et al. 2011).

\section{Base flow and low flow}

Streams can originate from different sources. The main sources are glaciers, overland flow due to precipitation and subsurface (groundwater) flow. Among these, the latter is the least variable source (Winter 2007) and therefore the role it plays in terms of sustainability should be considered carefully. This is especially true when groundwater provides a storage mechanism that can help to potentially mitigate negative effects of climate warming on the availability of water resources and maintaining river base flows.

Base flow is defined as the component of flow in a river which is not the direct consequence of the rainfall event but is considered as the outflow of the groundwater reservoir feeding the river during the rainless period (Frohlich et al. 1994). Nevertheless, base flow is typically investigated in 
the context of rainfall runoff studies in which it is separated from generated stream flow during precipitation. Regarding the importance of base flow in maintaining sustainability, few studies have investigated the mechanisms which generate stream flow during inter-storm/seasonal base flow periods (e.g. Kish et al. 2010; Payn et al. 2012). These mechanisms become important when the object is determining base flow (low flow indices) in ungauged catchments (sites). In the recent years, problems of droughts have focused attention on base flow periods and the processes sustaining water resources for both human consumption and ecosystem needs during dry spells (Jones et al. 2006b; Lehner et al. 2006). Nonetheless, base flows are often viewed as rather "dull", static periods compared with more "exciting" flood events. Furthermore, the processes contributing to low flows are often considered to be "simply" groundwater discharges to surface waters. In addition, in most cases base flow separation has been accomplished during a rainfall runoff simulation that does not help understand base flow processes seasonally, particularly when evapotranspiration is high. Additionally, a given system or reach may be losing during high flow/river stage but starts gaining as flow declines and the hydraulic gradient shifts toward the channel. Studies have shown that such two-way exchange does occur and that it can impact riparian groundwater and stream flow chemical composition long after floodwaters recede (Squillace 1996; Whitaker 2000; Baillie et al. 2007).

In many cases, the majority of stream flow discharge during low-flow periods is derived from groundwater storage releases (Smakhtin 2001). Low flow, as it was defined by the international glossary of hydrology (WMO 1974) is the "flow of water in a stream during prolonged dry weather". So, considering groundwater resources as reservoirs that could maintain sustainability as well as knowing how these reservoirs are operating are of great significance. The percentage contribution from groundwater to streams has been reported as high as $60 \%$ by Liu et al. (2004), $<75 \%$ by Clow et al. (2003) and up to $80-100 \%$ for snowmelt in three high elevation basins by Huth et al. (2004) [For more examples of the role of groundwater in maintaining base flow, readers are referred to Winter (2007)]. Using a multiple linear regression equation to predict seasonal low flows in Selwyn River in New Zealand, McKerchar and Schmidt (2007) concluded that low flows decreased at a rate of about $32 \mathrm{~L} / \mathrm{s}$ per year over the 22 years of recording. They attributed this decrease to groundwater abstraction and emphasized as well the role that groundwater could play in maintaining low flow.

To avoid seemingly different interpretations in sustaining stream flow, a distinction should be made between the water that is stored in the soil and moves through the phreatic zone (inter-flow or through-flow) and deep groundwater. Although there is rich literature on the importance of soil in sustaining base flow seasonally, it is not well documented how soil water interacts with base flow. Maybe the research done by Edlefsen and Bodman (1941) was one of the earliest in the context of soil water dependent base flow. They showed in a plot scale, which was soaked to a depth of $7 \mathrm{~m}$ by irrigation and sealed to prevent evaporation, that drainage was continuous over a period of 832 days. Nixon and Lawless (1960) calculated from moisture measurements the downward movement of approximately $28.5 \mathrm{~cm}$ of previously stored soil moisture (soil-water) from a $6 \mathrm{~m}$ profile of sandy soil during a 6-month dry season. They concluded that slow drainage from unsaturated soil may contribute significantly to groundwater recharge. Remson et al. (1960) indicated through their studies of an intermediate zone at Seabrook, New Jersey, USA, that downward gradients of hydraulic head produced slow but continuous rates of drainage even during the season of evapotranspiration.

Recent studies at the mesoscale (ca. $>100 \mathrm{~km}^{2}$ ) have shown that different parts of catchment landscapes can have markedly contrasting roles in low flow generation (Orr and Carling 2006; Peters et al. 2006). The aggregated effects of such spatial variation in catchment characteristics are often unclear. For example, using geochemical tracers and hydrometric data, Tetzlaff and Soulsby (2008) showed for a $1,849 \mathrm{~km}^{2}$ watershed in Scotland that periods of base flow were very dynamic for sub-catchments of the watershed, based on different reactions of sub catchments to isolated small rainfall events. The issue of diurnal variability in low flows is clearly an issue that warrants further study to identify the process controls (Wondzell et al. 2007). In addition, there are a few studies which have investigated the nature of interacting controls on low flow generation mechanisms in larger river systems $\left(>1,000 \mathrm{~km}^{2}\right)$. Due to the usual absence of major aquifers in montane headwaters, they are not considered as large contributors of base flow. Therefore, attentions are often shifted to larger groundwater resources in lowland areas as the assumed sources of base flows. According to Shaman et al. (2004) the two limiting factors for the lack of enough large-scale studies on controlling factors of low flow generation mechanisms are: (1) absence of tools that allow processes to be extrapolated from point scales to larger catchment scales (2) downstream increasing anthropogenic impacts in larger catchments and thus, masking natural variability. Tetzlaff and Soulsby (2008) stated that the role of headwater on groundwater in maintaining sustainable downstream low flow is not well recognized in the UK. They also emphasized that base flow generating mechanisms are more complex than what is believed.

Based on what has been explained above, it is clear that further research is needed to understand how base flows 
sustain water supplies and aquatic ecosystems, if appropriate management is sought to protect these catchment services from environmental change. We believe that better understanding of the interacting controls on low flow generation mechanisms can lead to better management of limited water resources.

\section{High flow}

The exerted role of subsurface flow has been shown to be of key importance in runoff generation. Pinder and Jones (1969) were among the first scientists who showed the influential contribution of groundwater in runoff by employing a mass balance equation for solutes. They showed that the groundwater component of runoff varied from 32 to $42 \%$ for three sub-basins in the US. To many, it might seem that groundwater movement speed is not fast enough to contribute to runoff generation, but it has been shown, through numerical and experimental studies, that subsurface flow can transmit water at rates sufficient to contribute to storm flow (Freeze 1972; Harr 1977; Pierson 1980; Fiori et al. 2007). Wenninger et al. (2004) showed that subsurface contribution was about $80 \%$ during a double peak flood event.

It should be mentioned that when the term subsurface flow is used, it could be the old water (pre-event) already stored in the catchment or new water (event water) that moves underground due to precipitation. Whether the subsurface flow contribution is dominated by old water or new water is still challenging due to different research results. For example, on one hand, Cloke et al. (2006) indicated that pre-event water played a minor role in runoff generation and just in a small number of cases high proportions of old water were observed at the outflow. On the other hand, applying a series of two-dimensional (2D) numerical simulations, Fiori and Russo (2007) concluded that the principal mechanism for stream flow generation in rainfall runoff processes is subsurface flow along the soilbedrock interface combined with groundwater ridging in the vicinity of the hillslope base. In fact, they determined pre-event water as the dominant discharge contributor to stream flow. This topic is discussed in detail in "Mechanisms".

It is generally agreed that once rain falls on the land surface, the unsaturated zone controls the separation of rainfall into surface runoff and infiltration. However, how and when the unsaturated zone starts to play this role is under intensive research. Some theories have been suggested from which three of them have been widely accepted. They are subsurface storm flow, variably saturated subsurface flow and partly saturated subsurface flow. These conceptualizations of runoff generation are discussed in detail in "Mechanisms". Generally, it is agreed that if the dominant mechanism is determined or observed, the way for estimating flood features in ungauged catchments is paved. In practical engineering, dominant mechanism or physics-based applications are rarely pursued. Instead, engineers apply a probability distribution model for estimating rare flood events for designing flood control structures. Although this approach is easy to use and may result in good estimations, particularly in catchments which have long flow records, it assumes that future events are similar to those previously observed (stationarity). In addition, this method is ill suited to address hydrologic responses to climate and/or land use changes. In summary, knowing peak flow generation mechanisms can lead to estimations which make sense physically and could also be applied in ungauged catchments as well as catchments in which long records of flow data do not exist.

With respect to high flows, there are two different kinds of challenges to be overcome by studying surface/subsurface interactions. On one hand, there are studies which argue the physical responsible mechanisms that convert the subsurface flow into stream discharge (Mcdonnell 1990; Weiler and Naef 2003; Cloke et al. 2006). On the other hand, there are articles which challenge the standard application of mass balance equations which are used as a basis to estimate subsurface flow contribution to stream flow. These equations are believed to lump the advective and dispersive/diffusive fluxes and thereby affect the interpretation of data (Chanat and Hornberger 2003; Jones et al. 2006a; Park et al. 2011). In the following, we review each of these viewpoints individually.

\section{Mechanisms}

Subsurface storm flow is defined as "the water that infiltrates through the ground surface, flows laterally toward the stream as unsaturated flow or shallow perched saturated flow and enters the stream through a seepage face that is above the stream flow level and below the line that the water table intersects the bank river" (Freeze 1974). Freeze (1974) described the terms "interflow" and "base flow" as part of the stream hydrograph that can be attributed to lateral inflow from the subsurface storm flow and groundwater flow, respectively. He divided the responsible mechanisms for runoff generation in an arbitrary classification into two categories: overland flow and subsurface storm flow.

The concept of runoff generation due to overland flow was first discussed by Horton (1933). He showed through some observations and empirical infiltration curve, that runoff happens if the rainfall intensity exceeds the infiltration capacity. Rubin (1966) showed that if unsaturated soil properties, initial soil moisture conditions, and rainfall 
intensity are known, the infiltration curves can be predicted. He identified rainfall rates greater than the saturated hydraulic conductivity and rainfall duration longer than the time required for soil to become saturated at the surface, as necessary conditions for overland flow generation. However, Freeze (1974) challenged the Hortonian runoff generation mechanism as the dominant mechanism. He inferred that two conditions are required to accept Horton concept as a runoff generating mechanism: (1) overland flow is generated when soil becomes saturated from above (the surface) by rainfall; (2) the runoff processes described by Horton are dominated in arid or semi-arid regions where rainfall intensity exceeds soil infiltration rates. Intensive studies in the beginning of the 1970s, particularly in humid vegetated areas, showed that Horton's concept could not justify runoff generation since rainfall intensity did/could not exceed infiltration rate in many cases. For example, in regions with sandy or gravelly soils, rainfall could not surpass infiltration rate, yet nearby stream flows increased [the reader is referred to papers by Rawitz et al. (1970) and Hills (1971)]. The overwhelming conclusion of all those studies was that overland flow was a rare occurrence in time and space in humid vegetated basins. So, the incapability/ inadequacy of Horton's concept in describing runoff processes led to two other theories named "partial area contribution" concept (Betson 1964), and "variable source area/variable saturated flow (VSF)" concept (Hewlett and Hibbert 1963; Hewlett 1974; Dahlke et al. 2012). Partial area contribution theory was based on regular overland flow contributions of some fixed parts of the watershed, whereas the concept of VSF assumed an expanding channel network wherein the channels reach out to tap the subsurface flow systems which have overridden their capacity to transmit water beneath the surface (Freeze 1974). The two major differences between these two theories are: (1) contracting/ expanding areas in VSF concept are not fixed parts as they are in partial area theory; (2) partial area concept assumes that saturation starts from above, whereas in VSF theory saturation initiates from below.

Although the theory of subsurface flow was discussed as one of the likely dominant mechanisms of stream flow generation in early works of Hewlett and Hibbert (1963), and Whipkey (1965), the theory did not get support from researchers until the late 1970s and early 1980s due to lack of enough evidence. Sklash and Farvolden (1979) showed through field observations, isotope applications and computer simulations that rapid increase in hydraulic head near streams caused groundwater ridging and was therefore responsible for rapid contributions of soil water to stream flow. Later, Gillham (1984) did a point-scale field experiment in which he showed the effect of the capillary fringe on water table fluctuations. He indicated that constant specific-yield-based prediction of a recharge value led to a number that was about 30 times away from reality. He then concluded that considering specific yield as a constant value to calculate recharge amounts results in tremendous errors, especially in areas where the water table is close to the ground surface. Therefore, he suggested the specific yield to be determined based on water content-pressure head relation (water retention curve) and the depth to the water table. He then expressed the idea of capillarity and specified that near-zero specific yield values are present in capillary fringe. To show the effectiveness of the capillary fringe theory on subsurface contribution, Abdul and Gillham $(1984,1989)$ designed lab and field experiments. Within their lab experiment, they designed a box $140 \mathrm{~cm}$ long, $8 \mathrm{~cm}$ wide, $120 \mathrm{~cm}$ high and packed it with medium fine sand in a way that the top right level of the sand stood at $108 \mathrm{~cm}$ and the left bottom was kept at the level of $80 \mathrm{~cm}$. Throughout the experiment, they maintained the water table at three different depths and applied rainfall at two different (high and low) intensities. Using chloride as a tracer, their experiment results indicated that the discharge of pre-event water to the pipe at the bottom of the slope proceeded event water, especially at early times of stream flow. They attributed the rapid movement of subsurface flow in the box to the capillary effect. Abdul and Gillham (1989) also conducted a field experiment in an area of $18 \mathrm{~m} \times 90 \mathrm{~m}$ in a shallow sandy aquifer at Canadian Forces Base Borden, Ontario, Canada. Based on their short interval water table measurements in their heavily instrumented site, they attributed the sharp rise of the water table in the vicinity of the man-made channel, flowing through the middle of the catchment, to capillarity. Their conclusion was very critical as they wrote "the temporal and spatial variations in the hydraulic-head and water table responses can only be explained by invoking the principles of the capillary fringe".

Jayatilaka and Gillham (1996) argued that capillarity is a key factor in controlling dynamics of near stream flow and that incorporation of capillary fringe effects in models could improve the representation of runoff processes as well as their enhanced predictive accuracy. Based on this work, they developed their own model named HECNAR. The model was based on the perception that a watershed can be divided into three zones based on their respective storage characteristics. Zone 1 was the area which extended up to a point in which the water table depth equaled the capillary fringe height. Zone 2 was considered the area where soil moisture was between field capacity and residual moisture, independent of the water table depth. Finally, the moisture deficient area, due to evapo transpirational losses, was named Zone 3. The assumptions that were made to approximate the physical system included isotropy and homogeneity of porous media, neglecting interception and depressional storages, and ignored water loss owing to 
evapotranspiration as it was assumed to be small within the duration of an event. They believed that "HECNAR incorporates the high discharge of subsurface water to the stream as a result of increased hydraulic gradient toward the stream".

McDonnell and Buttle (1998) challenged Jayatilaka and Gillham (1996) regarding the capillary-fringe-induced groundwater-ridging as the major mechanism of pre-event contributions to streams in near stream environments. They suggested alternative mechanisms such as preferential flow. In fact, they based their criticism on the observation of rapid water table responses in the absence of a capillary fringe. We also think that the assumption "water loss due to evapotranspiration could be neglected" in HECNAR contradicts the definition of Zone 3. McDonnell and Buttle (1998) inferred that the widespread applicability of groundwater ridging mechanism remains uncertain as rapid pre-event contributions to storm flow can originate from a range of hydrological processes. Moreover, they were confident that a conceptual paradox exists since the capillary fringe height of a soil is usually inversely related to its hydraulic conductivity. Therefore, the greater the tendency for capillary fringe rise, the less likely that rapid Darcian flux of groundwater can occur even with steepened hydraulic gradients in the near stream zone (Zaltsberg 1986; McDonnell and Buttle 1998). Cloke et al. (2006) took the laboratory experiment of Abdul and Gillham (1989) to validate the hypothesis of capillary fringe effect on pre-event contributions within a 2D finite element numerical model. They showed that while the ridge has not yet reached the surface, Darcian velocity vectors move away from, rather than toward, the channel to fill the area of storage in the unsaturated zone. In fact, they indicated through their simulation results that the ridge formation was not responsible for the pre-event contribution to the stream as the pre-event contribution started to begin when the surface pressure head equaled to zero. Afterwards, they showed the low proportion of pre-event water contribution to stream discharge, which was hypothesized to be due to groundwater ridging in specific conditions of the Abdul and Gillham (1984) laboratory experiment. They varied some influential variables and carried out a set of numerical simulations to look for evidence of groundwater ridging mechanism and pre-event contributions in other conditions. The variables which they varied were, initial water table depth, rainfall intensity, slope, saturated hydraulic conductivity, capillary fringe height, and volume of the sand box. It is beyond the scope of this paper to discuss the effects of individual and interrelated variables, however, the main findings of their numerical experiments were as follow:

1. Rainfall intensity was the most sensitive variable which influenced the portion of pre-event contribution, though its effect in ridge formation was limited to high hydraulically conductive areas where the capillary fringe did not reach the ground surface.

2. Whereas the capillary fringe was seen to be a controlling factor in ridge development, it had little effect on the pre-event water contribution.

3. Initial water table height had the maximum effect on both ridge development and domination of pre-event water discharge.

Park et al. (2011) also applied a numerical model to a simple catchment and concluded that capillarity cannot lead to enough mechanical flow. Based on the above discussion, groundwater ridging (capillarity), which has been debated over the last three decades, could not be relied on as an influential mechanism to explain subsurface flow contribution to runoff generation. We briefly review two other widely expected mechanisms in the following.

Pressure wave translatory flow

The mechanism is very analogues to variable saturated flow as it suggests that some subsurface layers will be saturated temporally and will extend in area and volume across slopes or large parts of catchments. Compared to the VSF mechanism, however, pressure wave translatory flow will initiate when continuous hydraulic connection is established across slopes and elevation zones, and thus individual groundwater bodies link together (Becker 2005). Burt and Butcher (1985) provided evidence to show the applicability of this mechanism by observing groundwater level fluctuation in a densely instrumented 1.4 ha hillslope in UK. They observed that as soon as previously disconnected groundwater bodies at bedrock interface merged and formed a continuous saturation layer across the slope, a secondary rise in stream flow occurred. Similar observations were reported in other catchments (Bazemore et al. 1994; Kirnbauer and Haas 1998; Torres et al. 1998; Becker 2005). Although the mechanism seems to be logical and makes sense physically, experimental evidence on this kind of subsurface runoff and the conditions that control it are poorly understood. In addition, quantifying different components of this perceptual model has not been widely done. For the most recent applications of pressure wave theory, readers are referred to Vidon (2012).

\section{Transmissivity feedback}

The mechanism is based on the idea that saturated hydraulic conductivity decreases as depth increases. In fact, transmissivity feedback is a special case of translatory flow where shallow groundwater displacement is enhanced by a decrease in saturated hydraulic conductivity with depth 
(Uhlenbrook and Hoeg 2003). This mechanism was first introduced by Bishop (1991) and since then it has been widely applied in the field of hillslope runoff generation. Cloke et al. (2006), for example, incorporated the method in a numerical experiment to test its applicability in explaining high amounts of observed pre-event water. They concluded that even though the water table levels rose rapidly, less stored (old/pre-event water) water was enabled as discharge due to decreased hydraulic conductivity (potential water movement). Bishop et al. (2011) described runoff response and quantified total water storage, flow paths, and vertical distribution of lateral flow in a catchment of $6,300 \mathrm{~m}^{2}$, using the principles of the transmissivity feedback runoff generation mechanism [for more applications of transmissivity in runoff generation, readers are referred to Kendall et al. (1999); Laudon et al. (2004); Detty and McGuire (2010)].

This variety of interacting processes, found in different environments, makes the estimation of how water enters the stream at a given site problematic without field investigations. We strongly believe that there is yet no broad consensus on how subsurface flow contributes to stream flow, even in one specific catchment or site. It goes without saying that first-order controls in one catchment may not be controlling factors in other catchments, depending on variation in geology, soil properties, rainfall features (duration and intensity), geometry, land use, etc. [for a review of how above-mentioned factors may affect stream flow generation, readers are referred to Bachmair and Weiler (2011)]. It seems that state variables are promising for generalization to similar catchments. Weiler and McDonnell (2004) argued that documenting idiosyncrasies of new hillslope environments should be replaced with defining generalizable appropriate state variables in different environments. They believe that if this shifting occurs, major experiments and excavations done in a specific hillslope/catchment will have transference value to a neighboring environment as a variety of properties change. Weiler and McDonnell (2004) developed a numerical physically based model, named HillVi, and explored the variation of drainable porosity as first-order control in hillslope hydrology. They tested their hypothesis (assuming drainable porosity as a first-order control) for a virtual hillslope by application of their model to simulate flow and transport for two different drainable porosity values while keeping other parameters and inputs constant. They concluded that drainable porosity can explain spatial and temporal variations of subsurface flow, saturation depth, tracer movement and its concentration as well.

\section{Tracers}

McGuire et al. (2007) argued that tracer experiments and their resulting breakthrough curves can be counted on as additional data sources which reflect the complexity of physical processes into one signal, like a hydrograph, as well as integrating flow heterogeneity and thus as tools that can constrain parameterization and reduce model uncertainty. Tracers can also delineate the origin of water (Chen et al. 2012). Nevertheless, the incorrect judgment based on their applications could end in misleading results.

In principle, the contribution of pre-event water can be derived based on the results of tracer data, which are interpreted using mass balance equations. The assumption that has been implicitly put into mass balance equations is that hydrodynamic mixing processes (such as mixing of pre-event and event water) are adequately accounted for in the calculation of the volumetric subsurface flow contribution (Jones et al. 2006a). To determine the proportion of event water and pre-event water with application of conservative tracers, it is very common to first sample subsurface water and rainwater to know their respective tracer signatures and then take multiple samples in the stream at regular time intervals during the storm and for a while after it has ended. Afterwards, based on different ratios of concentrations in the stream water and unit hydrograph, the above-mentioned proportion will be calculated. The key point about the hydrograph separation done this way is that it can only differentiate sources of water (event/pre-event) and cannot separate between water pathways (Jones et al. 2006a). In fact, there should be a clear distinction between temporal water sources (event/pre-event or old/new) and water flow pathways (overland or subsurface saturated/ unsaturated). Renaud et al. (2007) define pre-event water as the water that is stored in a catchment prior to the beginning of a rainfall event. It is very important to note that preevent water can follow different pathways to contribute to stream flow. Buttle (1994) accounted groundwater as only one out of six processes that can deliver pre-event water. In summary, it seems to be a necessity to scrutinize the efficiency of mass balance equation applications to better estimate the percentage of pre-event contribution.

VanderKwaak (1999) applied a finite element method to simulate the rainfall runoff experiment of Abdul and Gillham (1989) relying on a tracer-based separation method similar to that used by Abdul and Gillham (1989). He found significant discrepancy between model results (subsurface contribution) which were obtained when tracer (bromide) concentrations at the outlet were entered into mass balance equations and when nodal tracer fluxes were summed. Whereas he did not explicitly separate advective tracer contributions from dispersive/diffusive contributions to total solute fluxes entering the channel at each time step, he suggested that the discrepancy could have occurred due to dispersive/diffusive mixing processes at the surface subsurface interface. In light of the factors that can affect the strength of hydrodynamic mixing, Jones et al. (2006a) 
introduced mechanical dispersion, molecular diffusion, and rainfall intensity/duration as the influential factors. They conducted numerical experiments to compare the computed Darcian-based groundwater fluxes contributing to stream flow with estimates of those contributions based on trace-based separations. They found that contributions calculated based on the above two mentioned methods were significantly different. They attributed the difference to the hydrodynamic dispersion of event and pre-event water tracers. It was featured in their study that hydrodynamic mixing processes can dramatically affect estimates of pre-event water contributions based on tracer-based separation method, as well as demonstrating that the actual amount of groundwater contribution was smaller than tracer-based estimated amount even if the mixing processes were weak. Jones et al. (2006a) showed through their numerical simulations that event and unsaturated zone preevent waters mix with each other by means of dispersive/ diffusive processes before discharging into the channel. To further demonstrate the impact of dispersive/diffusive mixing processes on traditional based hydrograph separation, they assessed the influence of subsurface longitudinal dispersion, rainfall/intensity duration and multiple sequential rainfall events. Having increased the value of the dispersion coefficient, they observed a noticeable increase in the estimate of tracer-based pre-event contributions. In contrast, they decreased the coefficient to near zero. Then, the subsurface contribution minimally declined in comparison to the base case. They stated that even though the effect of mechanical mixing was eliminated, molecular diffusion can strongly influence the mixing process. To indicate the influence of rainfall intensity/ duration, they set two scenarios. In the first scenario, they increased rainfall intensity and decreased the duration and in the second one they did just the opposite. In both scenarios the volume of rainfall was maintained equal to the base case amount. They concluded that increased rainfall intensity leads to less tracer-based pre-event contribution, as event and pre-event waters have less time to hydrodynamically mix before being transmitted to the channel. The converse argument was also made regarding the effect of decreased intensity. Finally, they subjected the system to multiple sequential rainfalls separated by a 3-day recovery period. They observed that subsurface contribution decreased as it was expected. They attributed the decline to less mixturing of pre-event and event water as progressively more pre-event water would discharge from the system.

It should be noted that the challenging relationship of capillary fringe and pre-event contribution to stream flow was not clearly and explicitly discussed in Jones et al. (2006a). However, Park et al. (2011) later showed that the capillary fringe can accelerate the mixing of event and pre- event water parcels. Renaud et al. (2007) criticized Jones et al. (2006a) for not distinguishing between temporal sources and mechanical carriers of water contributions to stream flow. This issue was then discussed by Park et al. (2011) stating that the tracer technique for hydrograph separation to deduce the temporal origins of water entering a stream is influenced by pure mechanical flow processes. Also, Renaud et al. (2007) challenged Jones et al. for ignoring kinematic dispersion in water molecules as a potential source of error in estimating the pre-event contribution. Therefore, Renaud et al. (2007) stressed that diffusion and dispersion coefficients for water molecules themselves should be accounted for in modeling, to represent their travel through the subsurface, as well as parameterizing them based on site characteristics and tracer properties. Park et al. (2011) clarified the arguments of Renaud et al. (2007) and Sudicky et al. (2007) by showing that the "tracer technique for hydrograph separation to deduce the temporal origins of water entering a stream is influenced not only by pure mechanical flow processes, but also by mixing processes induced by potential chemical gradients".

Using the fully surface/subsurface integrated model of HydroGeoSphere (HGS), Park et al. (2011) analyzed the relationship between the spatial and temporal origins of storm flow in the stream as well as looking into how precipitation influences the flow in the catchment. To accomplish that, two cross-sections, parallel (A) and perpendicular (B) to the stream, of a simplified virtual catchment were assumed. To maintain simplicity, they ignored evaporation and transpiration and assumed uniformity and isotropy of hydraulic properties. Regarding the simulation in plane (A), they observed that pre-event discharge increased far greater than the mechanical subsurface flow component as rainfall intensity augmented. They ascribed the strong pre-event stream discharge, often interpreted based on conventional tracer-based hydrograph separations, to added effects of diffusion and mechanical dispersion. As it is generally accepted (e.g. McDonnell 1990; Weiler and Naef 2003) that considering macropores in porous media can explain the high contribution of preevent water, Park et al. (2011) applied a dual-permeability approach (Gerke and Van Genuchten 1993) by attributing $1 \%$ of the bulk volume a high hydraulic conductivity value to test this hypothesis. While they considered an arbitrary value of $1 \%$ as the simulated bulk volume occupied by macropores, results showed that mechanical contribution of subsurface flow increased, whereas their contribution diminished as rainfall intensity rose again due to further mixing. They concluded that "compared to single continuum simulation cases, pre-event water contributes more to the total stream discharge because of enhanced mechanical input of water and because of the enhanced dispersive input 
to the stream induced by macropores". In plane (B), perpendicular to the stream, while pre-event unsaturated discharge ratio to saturated portion incremented due to increase in rainfall intensity, the ratio of increase in exfiltration values (mechanical mechanism) did not reconcile. These results led them to the conclusion that "capillary fringe groundwater ridging may not generate enough mechanical flow for observed pre-event discharge, but it may accelerate mixing processes such that more pre-event water discharges to the stream". They reached the same conclusion in plane (B) as in plane (A) saying that preevent water contribution by mechanical flow processes to the stream discharge is limited without dispersion. Results of dual-continuum simulation in plane (B) were similar to those derived for plane (A).

\section{Modeling}

Models as useful hypothesis testing tools enable us to study combinations of conditions which have not yet been encountered in field studies or cannot be replicated at field scale (Johansson 1985). Recently, physics-based models have been vastly utilized to simulate short-term (eventbased) and long-term interactions of subsurface surface flow on the premise that such models can account for internal processes and complexities (Jones et al. 2008; James et al. 2010; Mirus et al. 2011) and hence could be applied in ungauged catchments. Assuming the abovementioned assumption is true, the question that quickly follows is: why such models are calibrated? McDonnell et al. (2007) answer this question quoting "models based on current theories rely on calibration to account for our lack of knowledge of the spatial heterogeneities in landscape properties and to compensate for the lack of understanding of actual processes and process interactions".

With respect to process understanding, around three decades ago, Dooge (1986) published a paper titled "Looking for hydrologic laws" and asked for new visions in the science of hydrology. Dooge suggested a new framework for developing new theories including: (1) searching for new macroscale laws (2) developing scaling relations across watershed scales, and (3) upscaling from small-scale theories. Despite showing the inefficiencies in recent physics-based large-scale (field scale) model simulation (James et al. 2010), it is surprising that after about 26 years Dooge's suggestions have not been fully pursued. Meanwhile, it is worth mentioning that some alternative concepts such as Representative Elementary Watersheds (Reggiani et al. 1998, 2000; Zhang and Savenije 2005) or Hydrological Response Units (Kouwen et al. 1993; Flugel 1995; Viviroli et al. 2009) have been introduced. DarcyRichards equation, which is the foundation of many physics-based models, as a subgrid-scale parameterization approach is often consistent with the point-scale measurements (tensiometers, TDR, etc.) in soils which are dominated by matrix flow. Nevertheless, it often breaks down at larger scales or in soils dominated by preferential flow (Weiler and Naef 2003). Furthermore, spatial discretization of Richard's equation is another issue whose limits have been addressed in many papers (van Dam and Feddes 2000; Downer and Ogden 2003). Vogel and Ippisch (2008) showed critical spatial discretization length at unit gradient in a typical sand is about $5 \mathrm{~cm}$. They stated that if spatial discretization goes beyond its critical limit, convergence of the solver and accuracy of the solution would be influenced.

The Type of data we currently collect is another issue that hinders the ideal application of 3-D physical based models in catchment scale as such data types cannot fully characterize the catchment (Loague et al. 2005). It is now widely accepted in the hydrologic community that laboratory data or even data collected at individual points in the field are of limited value in parameterizing large-scale modeling (James et al. 2010; Doherty and Christensen 2011). Recent approaches, such as combined application of geophysical and hydrogeological data to delineate subsurface heterogeneity (Doro et al. 2013) should be pursued and developed. So, we strongly believe that as long as we cannot establish new methods or invent new devices which can account for macro-scale processes as well as those micro-scale ones, applications of highly parameterized 3-D physics-based models are not promising.

Doherty and Christensen (2011) appreciated the value of micro scale physics-based simulations as they wrote "complex numerical models have the advantages of allowing representation of complex processes and heterogeneous system property distributions inasmuch as these are understood at any particular study site". On the other hand, they challenged application of complex models due to their long run times, occasional numerical instability, and analysis of their predictive uncertainty. There is a broad consensus that such heavily parameterized models lead to high predictive uncertainty (Beven 2000). One more issue that is addressed well by Brunner et al. (2012) is the worth of observation data in identification of parameters (parameter identifiability) and predictive uncertainty. One conceptual relationship between model complexity, data availability and predictive performance is illustrated in Fig. 1. As indicated in Fig. 1, for a limited to moderate amount of data, increasing model complexity leads to reduction in model performance.

Having reviewed the misleading large-scale application of available physics-based models, we strongly believe that such models that consider internal dynamic processes are valuable learning tools provided that the uncertainty is 
Fig. 1 Relationship between model complexity, data availability and model performance (from Grayson and Blöschl, 2001)

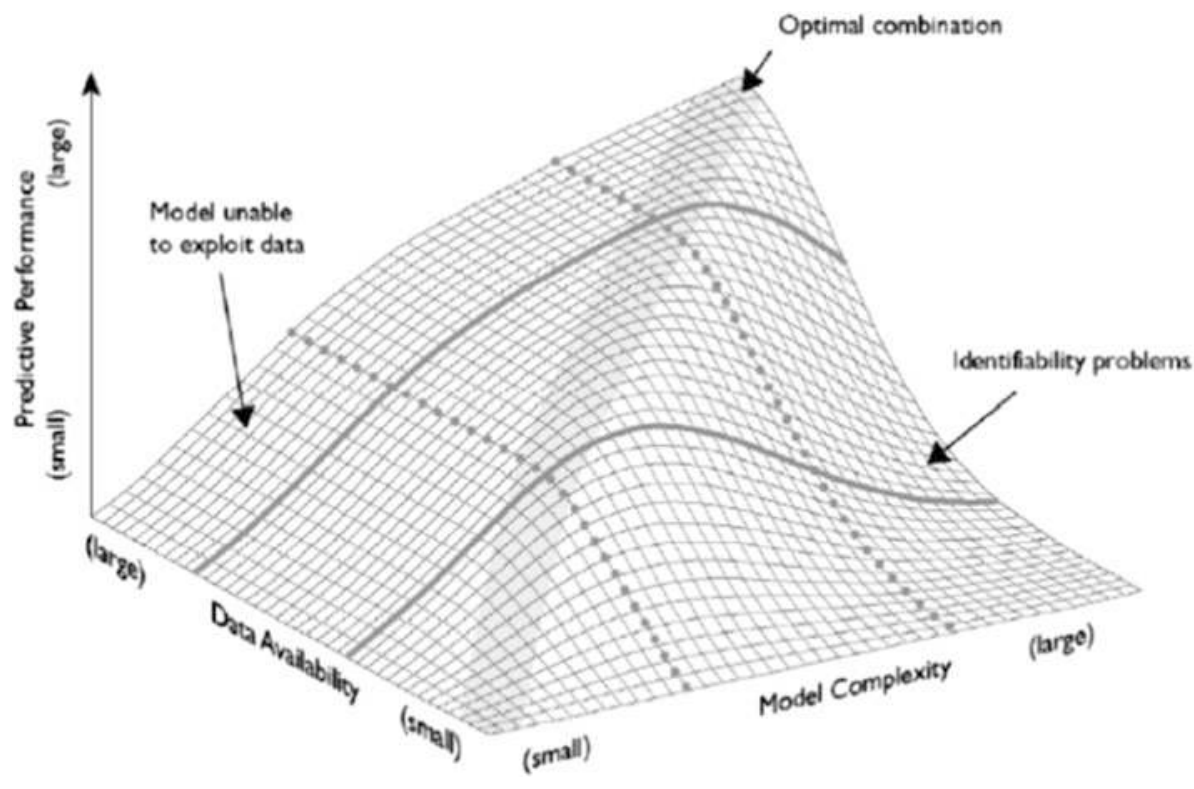

reduced. Loague et al. (2006) argue that 3-D physics-based models provide foundations for understanding coupled systems at hillslope scale, give new understanding and prompt new experiments. Bredehoeft (2010) introduces models as tools to organize our thinking. He emphasizes that by writing "For me the model is not an end in itself, but rather a powerful tool that organizes my thinking and my engineering judgment". We fully agree with the statement which was first suggested by Ebel and Loague (2006) and then was emphasized by James et al. (2010) saying " ... the value of physics-based simulation of hillslope and small catchment response will be the examination of their failure to replicate experimental observations and the changes it will bring about to the models themselves".

\section{Concluding remarks and challenges ahead}

In summary, new approaches should not rely on calibration, but rather on systematic learning from observed data, and on increased understanding and search for new hydrologic theories through embracing new organizing principles behind watershed behavior that are derived from our sister disciplines (McDonnell et al. 2007). As Cloke et al. (2006) point out in their paper, most field environments have complex geometries which are very different from lab experiments. Water table topography is a clear example. Moreover, we believe that much of the research in the field of modeling hillslope hydrology needs revision. It should be noted that modeling micro scale (lab experiments) can be beneficial. However, what matters to decision makers is the potential application of hydrology in solving practical problems at catchment or watershed scales. This issue requires more test cases including experimental data sets from lab scale to real world catchments (Grathwohl et al. 2013). Regarding that, transit time distribution, for example, has been shown to be promising in representing integrated responses of diverse flow pathways in hillslope and catchment scale and thus connecting process complexity with model simplification (McGuire et al. 2007; Doherty and Christensen 2011). Since many catchments and large-scale applications are concerned with water quality aspects such as acidification (Stoddard et al. 1999), cumulative effects (Sidle and Hornbeck 1991) and nutrient cycling (Creed and Band 1998), the age or transit time of water offers a link to water quality since the contact time in the subsurface largely controls stream chemical composition, revealing information about the storage, flow pathways and sources of water in a single measure (McGuire and McDonnell 2006; McGuire et al. 2007).

With respect to the above-mentioned challenges, the authors intend to simulate the transient behavior of the Rietholzbach catchment, which is a pre-alpine $3 \mathrm{~km}^{2}$ catchment in Switzerland (Seneviratne et al. 2012), including temporal and spatial contribution of subsurface flow to stream flow. To achieve this target, we believe that if dominant processes and state variables are identified in a smaller scale, there would be higher chances to simulate the behavior of the catchment fast and generalize the modeling results to the neighboring catchments as well. Hydrogeosphere (HGS) which is a three-dimensional numerical model describing fully integrated subsurface and surface flow and solute transport will be used as a simulation tool in our study. To the knowledge of the authors, the model has rarely been used as a learning tool for testing 
hypothesis. We intend to apply HGS in a heavily instrumented field site in the catchment in order to evaluate the model assumptions in modeling surface water bodies interactions with subsurface media as well as testing some hydrological hypothesis. It is also planned to conduct some new experiments in locations and times that the model fail. We believe the new experiments will provide us with worthwhile data that may reveal some unknown facts. We welcome any kind of collaboration on tracer-based characterization of ongoing processes at the field site and catchment scale, as well as modeling techniques, including model simplification and model structure uncertainty analysis.

Acknowledgments This study was financed by the Competence Center Environment and Sustainability (CCES) of the ETH domain in the framework of the RECORD Catchment (Coupled Ecological, Hydrological and Social Dynamics in Restored and Channelized Corridors of a River at the Catchment Scale) project. In addition, this work was supported by the Swiss National Science Foundation (SNF grant 200021-129735 “Alpine Hydrogeology"). The first author is holding a PhD Scholarship from the Iranian Ministry of Science and Technology. We wish to thank Jana von Freyberg for discussions. We also appreciate the beneficial and timely comments of the reviewers, which improved the consistency and clarity of the paper.

\section{References}

Abdul AS, Gillham RW (1984) Laboratory studies of the effects of the capillary-fringe on streamflow generation. Water Resour Res 20(6):691-698

Abdul AS, Gillham RW (1989) Field studies of the effects of the capillary-fringe on streamflow generation. J Hydrol 112(1-2):1-18

Bachmair S, Weiler M (2011) New dimensions of hillslope hydrology. In: Levia D, Carlyle-Moses D, Tanaka T (eds) forest hydrology and biogeochemistry

Baillie MN, Hogan JF, Ekwurzel B, Wahi AK, Eastoe CJ (2007) Quantifying water sources to a semiarid riparian ecosystem, San pedro river, Arizona. J Geophys Res-Biogeo 112(G3)

Bazemore DE, Eshleman KN, Hollenbeck KJ (1994) The role of soilwater in stormflow generation in a forested headwater catchment-synthesis of natural tracer and hydrometric evidence. J Hydrol 162(1-2):47-75

Becker A (2005) Runoff processes in mountain headwater catchments: recent understanding and research challenges. In: Huber UM, Bugmann HKM, Reasoner MA (eds) Global change and mountain regions. Springer, Netherlands, pp 283-295

Betson RP (1964) What is watershed runoff. J Geophys Res 69(8):1541

Beven KJ (2000) Uniqueness of place and process representations in hydrological modelling. Hydrol Earth Syst Sci 4(2):203-213

Bishop KH (1991) Episodic increase in stream acidity, catchment flow pathways and hydrograph separation, $\mathrm{PhD}$ thesis, University of Cambridge, $246 \mathrm{pp}$

Bishop K, Seibert J, Nyberg L, Rodhe A (2011) Water storage in a till catchment II Implications of transmissivity feedback for flow paths and turnover times. Hydrol Process 25(25):3950-3959

Bredehoeft J (2010) Models and model analysis. Ground Water 48(3):328

Brunner P, Doherty J, Simmons CT (2012) Uncertainty assessment and implications for data acquisition in support of integrated hydrologic models. Water Resour Res 48:W07513
Burt TP, Butcher DP (1985) On the generation of delayed peaks in stream discharge. J Hydrol 78(3-4):361-378

Buttle JM (1994) Isotope hydrograph separations and rapid delivery of pre-event water from drainage basins. Prog Phys Geog 18(1):16-41

Chanat JG, Hornberger GM (2003) Modeling catchment-scale mixing in the near-stream zone-Implications for chemical and isotopic hydrograph separation. Geophys Res Lett 30(2):1091

Chen JS, Liu XY, Wang CY, Rao WB, Tan HB, Dong HZ, Sun XX, Wang YS, Su ZG (2012) Isotopic constraints on the origin of groundwater in the Ordos Basin of northern China. Environ Earth Sci 66(2):505-517

Cloke HL, Anderson MG, McDonnell JJ, Renaud JP (2006) Using numerical modelling to evaluate the capillary fringe groundwater ridging hypothesis of streamflow generation. J Hydrol 316(1-4): 141-162

Clow DW, Schrott L, Webb R, Campbell DH, Torizzo A, Dornblaser M (2003) Ground water occurrence and contributions to streamflow in an alpine catchment colorado front range. Ground Water 41(7):937-950

Creed IF, Band LE (1998) Exploring functional similarity in the export of nitrate- $\mathrm{N}$ from forested catchments: a mechanistic modeling approach. Water Resour Res 34(11):3079-3093

Dahlke HE, Easton ZM, Lyon SW, Walter MT, Destouni G, Steenhuis TS (2012) Dissecting the variable source area concept - subsurface flow pathways and water mixing processes in a hillslope. J Hydrol 420-421:125-141

Detty JM, McGuire KJ (2010) Topographic controls on shallow groundwater dynamics: implications of hydrologic connectivity between hillslopes and riparian zones in a till mantled catchment. Hydrol Process 24(16):2222-2236

Doherty J, Christensen S (2011) Use of paired simple and complex models to reduce predictive bias and quantify uncertainty. Water Resour Res 47:W12534

Dooge JCI (1986) Looking for hydrologic laws. Water Resour Res 22(9):S46-S58

Doro KO, Leven C, Cirpka OA (2013) Delineating subsurface heterogeneity at the Steinlach River Loop using geophysical and hydrogeological methods. Environ Earth Sci 69(2). doi: 10.1007/s12665-013-2316-0

Downer CW, Ogden FL (2003) Prediction of runoff and soil moistures at the watershed scale: Effects of model complexity and parameter assignment. Water Resour Res 39(3):1045-1058

Ebel BA, Loague K (2006) Physics-based hydrologic-response simulation: seeing through the fog of equifinality. Hydrol Process 20(13):2887-2900

Edlefsen NE, Bodman GB (1941) Field measurements of water movement through a silt loam soil. Amer. Soc. Agron. J 33:713-731

Fiori A, Romanelli M, Cavalli DJ, Russo D (2007) Numerical experiments of streamflow generation in steep catchments. J Hydrol 339(3-4):183-192

Fiori A, Russo D (2007) Numerical analyses of subsurface flow in a steep hillslope under rainfall: The role of the spatial heterogeneity of the formation hydraulic properties. Water Resour Res 43(7):W07445

Flugel WA (1995) Delineating hydrological response units by geographical information-system analyses for regional hydrological modeling using $\mathrm{prms} / \mathrm{mms}$ in the drainage-basin of the River Brol, Germany. Hydrol Process 9(3-4):423-436

Freeze RA (1972) Role of subsurface flow in generating surface runoff. 1. base flow contributions to channel flow. Water Resour Res 8(3):609

Freeze RA (1974) Streamflow generation. Rev Geophys 12(4):627-647

Frohlich K, Frohlich W, Wittenberg H (1994) Determination of ground-water recharge by baseflow separation-regional analysis in Northeast China. 2nd international conference on flow 
regimes from international experimental and network data 221:69-75

Gerke HH, Van Genuchten MT (1993) A dual-porosity model for simulating the preferential movement of water and solutes in structured porous-media. Water Resour Res 29(2):305-319

Gillham RW (1984) The capillary-fringe and its effect on water-table response. J Hydrol 67(1-4):307-324

Grathwohl P, Rügner H, Wöhling T, Osenbrück K, Schwientek M, Gayler S, Wollschläger U, Selle B, Pause M, Delfs J-O, Grzeschik M, Weller U, Ivanov M, Cirpka OA, Maier U, Kuch B, Nowak W, Wulfmeyer V, Warrach-Sagi K, Streck T, Attinger S, Bilke L, Dietrich P, Fleckenstein JH, Kalbacher T, Kolditz O, Rink K, Samaniego L, Vogel H-J, Werban U, Teutsch G (2013) Catchments as reactors-a comprehensive approach for water fluxes and solute turn-over. Environ Earth Sci. 69(2), doi: 10.1007/s12665-013-2281-7

Grayson R, Blöschl G (2001) Spatial patterns in catchment hydrology: observations and modelling. Cambridge University Press, New York, p 404

Harr RD (1977) Water flux in soil and subsoil on a steep forested slope. J Hydrol 33(1-2):37-58

Hewlett JD (1974) Letters relating to role of subsurface flow in generating surface runoff.2. upstream source areas by freeze, Ra. Water Resour Res 10(3):605-607

Hewlett JD, Hibbert AR (1963) Moisture and energy conditions within a sloping soil mass during drainage. J Geophys Res 68(4):1081

Hills RC (1971) The influence of land management and soil characteristics on infiltration and the occurrence of overland flow. J Hydrol 13:163-181

Horton RE (1933) The role of infiltration in the hydrologic cycle. Eos T Am Geophys Un 14:446-460

Huth AK, Leydecker A, Sickman JO, Bales RC (2004) A twocomponent hydrograph separation for three high-elevation catchments in the Sierra Nevada California. Hydrol Process 18(9):1721-1733

James AL, McDonnell JJ, Tromp-van Meerveld I, Peters NE (2010) Gypsies in the palace: experimentalist's view on the use of 3-D physics-based simulation of hillslope hydrological response. Hydrol Process 24(26):3878-3893

Jayatilaka CJ, Gillham RW (1996) A deterministic-empirical model of the effect of the capillary fringe on near-stream area runoff.1. Description of the model. J Hydrol 184(3-4):299-315

Johansson B (1985) A study of soilwater and groundwater-flow of hillslopes—using a mathematical-model. Nord Hydrol 16(2):67-78

Jones JP, Sudicky EA, Brookfield AE, Park YJ (2006a) An assessment of the tracer-based approach to quantifying groundwater contributions to streamflow. Water Resour Res 42(2):W02407

Jones PD, Lister DH, Wilby RL, Kostopoulou E (2006b) Extended riverflow reconstructions for England and Wales, 1865-2002. Int J Climatol 26(2):219-231

Jones JP, Sudicky EA, McLaren RG (2008) Application of a fullyintegrated surface-subsurface flow model at the watershed-scale: A case study. Water Resour Res 44(3):W03407

Kendall KA, Shanley JB, McDonnell JJ (1999) A hydrometric and geochemical approach to test the transmissivity feedback hypothesis during snowmelt. J Hydrol 219(3-4):188-205

Kirnbauer R, Haas P (1998) Observations on runoff generation mechanisms in small Alpine catchments, Hydrology. Water Resour Ecol Headwaters 248:239-247

Kish GR, Stringer CE, Stewart MT, Rains MC, Torres AE (2010) A geochemical mass-balance method for base-flow separation, upper hillsborough river watershed, west-central florida, 2003-2005 and 2009. Sci Investig Rep 2010-5092:1-33

Kouwen N, Soulis ED, Pietroniro A, Donald J, Harrington RA (1993) Grouped response units for distributed hydrologic modeling. J Water Res Pl-Asce 119(3):289-305
Laudon H, Seibert J, Kohler S, Bishop K (2004) Hydrological flow paths during snowmelt: Congruence between hydrometric measurements and oxygen 18 in meltwater, soil water, and runoff. Water Resour Res 40(3):W03102

Lehner B, Doll P, Alcamo J, Henrichs T, Kaspar F (2006) Estimating the impact of global change on flood and drought risks in europe: a continental, integrated analysis. Clim Ch 75(3):273-299

Liang DF, Falconer RA, Lin BL (2007) Coupling surface and subsurface flows in a depth averaged flood wave model. J Hydrol 337(1-2):147-158

Liu L, Cheng SY, Guo HC (2004) A simulation-assessment modeling approach for analyzing environmental risks of groundwater contamination at waste landfill sites. Hum Ecol Risk Assess 10(2):373-388

Loague K, Heppner CS, Abrams RH, Carr AE, VanderKwaak JE, Ebel BA (2005) Further testing of the Integrated Hydrology Model (InHM): event-based simulations for a small rangeland catchment located near Chickasha Oklahoma. Hydrol Process 19(7):1373-1398

Loague K, Heppner CS, Mirus BB, Ebel BA, Ran QH, Carr AE, BeVille SH, VanderKwaak JE (2006) Physics-based hydrologicresponse simulation: foundation for hydroecology and hydrogeomorphology. Hydrol Process 20(5):1231-1237

Mcdonnell JJ (1990) A rationale for old water discharge through macropores in a steep humid catchment. Water Resour Res 26(11):2821-2832

McDonnell JJ, Buttle JM (1998) Comment on "A deterministicempirical model of the effect of the capillary-fringe on nearstream area runoff. 1. Description of the model" by Jayatilaka, C. J. and Gillham R. W (J Hydrol 184 (1996) 299-315). J Hydrol 207(3-4):280-285

McDonnell JJ, Sivapalan M, Vache K et al (2007) Moving beyond heterogeneity and process complexity: a new vision for watershed hydrology. Water Resour Res 43(7):W07301

McGuire KJ, McDonnell JJ (2006) A review and evaluation of catchment transit time modeling. J Hydrol 330(3-4):543-563

McGuire KJ, Weiler M, McDonnell JJ (2007) Integrating tracer experiments with modeling to assess runoff processes and water transit times. Adv Water Resour 30(4):824-837

McKerchar AI, Schmidt J (2007) Decreases in low flows in the lower Selwyn River? J Hydrol (NewZealand) 46(2):63-72

Mirus BB, Ebel BA, Heppner CS, Loague K (2011) Assessing the detail needed to capture rainfall-runoff dynamics with physicsbased hydrologic response simulation. Water Resour Res 47:W0OH10

Nixon PR, Lawless GP (1960) Translocation of moisture with time in unsaturated soil profiles. J Geophys Res 65(2):655-661

Orr HG, Carling PA (2006) Hydro-climatic and land use changes in the river lune catchment, North West England, implications for catchment management. River Res Appl 22(2):239-255

Park YJ, Sudicky EA, Brookfield AE, Jones JP (2011) Hydrologic response of catchments to precipitation: quantification of mechanical carriers and origins of water. Water Resour Res 47:W02425

Payn RA, Gooseff MN, McGlynn BL, Bencala KE, Wondzell SM (2012) Exploring changes in the spatial distribution of stream baseflow generation during a seasonal recession. Water Resour Res 48:W04519

Peters E, Bier G, van Lanen HAJ, Torfs PJJF (2006) Propagation and spatial distribution of drought in a groundwater catchment. J Hydrol 321(1-4):257-275

Pierson TC (1980) Piezometric response to rainstorms in forested hillslope drainage depressions. J Hydrol (New Zealand) 19(1):1-10

Pinder GF, Jones JF (1969) Determination of ground-water component of peak discharge from chemistry of total runoff. Water Resour Res 5(2):438-445 
Rawitz E, Engman ET, Cline GD (1970) Use of mass balance method for examining role of soils in controlling watershed performance. Water Resour Res 6(4):1115-1123

Reggiani P, Sivapalan M, Hassanizadeh SM (1998) A unifying framework for watershed thermodynamics: balance equations for mass, momentum, energy and entropy, and the second law of thermodynamics. Adv Water Resour 22(4):367-398

Reggiani P, Sivapalan M, Hassanizadeh SM (2000) Conservation equations governing hillslope responses: exploring the physical basis of water balance. Water Resour Res 36(7):1845-1863

Remson I, Randolph JR, Barksdale HC (1960) The zone of aeration and ground-water recharge in sandy sediments at Seabrook. Soil Sci 893:145-156

Renaud JP, Cloke HL, Weiler M (2007) An assessment of the tracerbased approach to quantifying groundwater contributions to streamflow-comment. Water Resour Res 43(9):W09301

Rubin J (1966) Theory of rainfall uptake by soils initially drier than their field capacity and its applications. Water Resour Res 2(4):739

Seneviratne SI, Lehner I, Gurtz J et al (2012) Swiss prealpine Rietholzbach research catchment and lysimeter:32 year time series and 2003 drought event. Water Resour Res 48(6):W06526

Shaman J, Stieglitz M, Burns D (2004) Are big basins just the sum of small catchments? Hydrol Process 18(16):3195-3206

Sidle RC, Hornbeck JW (1991) Cumulative effects-a broader approach to water-quality research. J Soil Water Conserv 46(4):268-271

Sklash MG, Farvolden RN (1979) Role of groundwater in storm runoff. J Hydrol 43(1-4):45-65

Smakhtin VU (2001) Low flow hydrology: a review. J Hydrol 240(3-4):147-186

Squillace PJ (1996) Observed and simulated movement of bankstorage water. Ground Water 34(1):121-134

Stoddard JL, Jeffries DS, Lukewille A et al (1999) Regional trends in aquatic recovery from acidification in North America and Europe. Nature 401(6753):575-578

Sudicky EA, Jones JP, Brookfield AE, Park YJ (2007) An assessment of the tracer-based approach to quantifying groundwater contributions to streamflow-comment-reply. Water Resour Res 43(9):W09602

Tetzlaff D, Soulsby C (2008) Sources of baseflow in larger catchments-using tracers to develop a holistic understanding of runoff generation. J Hydrol 359(3-4):287-302

Torres R, Dietrich WE, Montgomery DR, Anderson SP, Loague K (1998) Unsaturated zone processes and the hydrologic response of a steep, unchanneled catchment. Water Resour Res 34(8): $1865-1879$

Uhlenbrook S, Hoeg S (2003) Quantifying uncertainties in tracerbased hydrograph separations: a case study for two-, three- and five-component hydrograph separations in a mountainous catchment. Hydrol Process 17(2):431-453 van Dam JC, Feddes RA (2000) Numerical simulation of infiltration, evaporation and shallow groundwater levels with the Richards equation. J Hydrol 233(1-4):72-85

VanderKwaak JE (1999) Numerical simulation of flow and chemical transport in integrated surface-subsurface systems $\mathrm{PhD}$ thesis, University of Waterloo, Ontario, Canada

Vidon P (2012) Towards a better understanding of riparian zone water table response to precipitation: surface water infiltration, hillslope contribution or pressure wave processes? Hydrol Process 26(21):3207-3215

Viviroli D, Zappa M, Gurtz J, Weingartner R (2009) An introduction to the hydrological modelling system PREVAH and its pre- and post-processing-tools. Environ Modell Softw 24(10):1209-1222

Vogel HJ, Ippisch O (2008) Estimation of a critical spatial discretization limit for solving Richards' equation at large scales. Vadose Zone J 7(1):112-114

Weiler M, McDonnell J (2004) Virtual experiments: a new approach for improving process conceptualization in hillslope hydrology. J Hydrol 285(1-4):3-18

Weiler M, Naef F (2003) Simulating surface and subsurface initiation of macropore flow. J Hydrol 273(1-4):139-154

Weill S, Mazzia A, Putti M, Paniconi C (2011) Coupling water flow and solute transport into a physically-based surface-subsurface hydrological model. Adv Water Resour 34(1):128-136

Wenninger J, Uhlenbrook S, Tilch N, Leibundgut C (2004) Experimental evidence of fast groundwater responses in a hillslope/ floodplain area in the black forest mountains Germany. Hydrol Process 18(17):3305-3322

Whipkey RZ (1965) Subsurface stormflow from forested slopes. Bull Int Assoc Sci Hydrol 10(2):74-85

Whitaker MPL (2000) Estimating bank storage and evapotranspiration using soil physical and hydrological techniques in a gaining reach of the San Pedro River, Arizona, Ph.D thesis, University of Arizona

Winter TC (2007) Role of ground water in generating streamflow in headwater areas and in maintaining base flow. J Am Water Resour Assoc 43(1):15-25

Winter TC, Harvey JW, Lehn Franke O, Alley WM (1998) Ground water and surface water-a single resource Rep

WMO (1974) Rep., World Meteorological Organization, Geneva

Wondzell SM, Gooseff MN, McGlynn BL (2007) Flow velocity and the hydrologic behavior of streams during baseflow. Geophys Res Lett 34(24):L17404

Zaltsberg E (1986) Laboratory studies of the effects of the capillaryfringe on streamflow generation by Abdul, a.s. and Gillham, R.W.-comment. Water Resour Res 22(5):837-838

Zhang GP, Savenije HHG (2005) Rainfall-runoff modelling in a catchment with a complex groundwater flow system: application of the Representative Elementary Watershed (REW) approach. Hydrol Earth Syst Sci 9(3):243-261 